\title{
LA FILLE DE NANA-BENZ DE EDWIDGE EDORH ${ }^{12}$
}

\section{Gabriella Giansante*}

A literatura francófona, diferentemente da francesa, somente se afirmou na segunda metade do século XX, gerando uma diferenciação entre literatura francófona ${ }^{3}$ (no singular), que indica o conjunto de textos literários escritos em língua francesa, e literaturas francófonas (no plural), que indica o conjunto de textos em língua francesa que remetem a países ou regiões fora do hexágono e que contribuem para formar sua identidade. Estas definições, no entanto, permaneceram por muito tempo problemáticas.

Inicialmente as literaturas francófonas eram definidas como regionais, periféricas, ultramarinas ou simplesmente de expressão francesa, tanto que na enciclopédia da Pléiade 4 foram reunidas como literaturas conexas. Elas já se manifestavam desde o nascimento do termo francofonia, mas ganharam força e vitalidade somente nos anos 1960, depois da descolonização.

O termo francofonia foi cunhado pelo geógrafo Onésime Reclus ${ }^{5}$. As pesquisas, orientadas ao estudo da França e da África do Norte, nele desenvolveram a ideia de poder classificar os habitantes do planeta segundo a língua falada na família e nas relações sociais. Ele calculou, baseado neste critério, até mesmo quantos eram os homens no mundo que falavam francês, estabelecendo assim o conjunto da população francófona.

\footnotetext{
1 Texto originalmente publicado em italiano na Revista Bérénice (Rivista quadrimestrale di Studi Comparati e ricerche sulle Avanguarde, XIII, 33, marzo 2005), ISSN: 1128-7047 (p. 54-59).

2 Tradutor: João Vicente. Doutor em Literatura pela Universidade de Brasília (UnB) com tese que tratou, dentre outros, do romance em análise neste texto.

* Departamento de Letras, Artes e Ciências Sociais, (Língua, Literatura e Cultura Francesa) da Università degli Studi "Gabriele d'Annunzio" de Chieti-Pescara.

${ }^{3}$ [Nota de Tradução] Os termos aparecem em francês, no texto em italiano. Optamos pela tradução para o português, porém mantivemos o destaque com o uso de itálicos.

${ }^{4}$ [Nota da autora] Encyclopédie de la Pléiade, Paris, Gallimard, 1958

5 [N.A.] A criação do termo remonta a 1880.
} 
É preciso especificar que a palavra francofonia no momento de sua criação assume duas valências: uma geográfica e uma linguística.

Foi somente mais tarde, nos anos 1970 que se somou a valência cultural, como bem explica Auguste Viatte ${ }^{6}$ coautor do Dictionnaire général de la francophonie ${ }^{7}$ autor de La francopho$n i e^{8}$. De fato, para ele, a diferença decorrente entre o adjetivo english, que significa a nacionalidade, e british, adjetivo cultural, que indica uma comunidade de espírito, vale para français e francophone.

A valência cultural é, depois, institucionalizada com Georges Pompidou, o qual afirmou que o princípio da francofonia é o de unir os povos de língua e cultura francesa, assim como por interesses econômicos ou políticos, sobretudo por ligação intelectual e espiritual.

Especificamos que quando falamos de valor espiritual entendemos o sentimento que une um povo.

Em 1969 a França participou com André Malraux da primeira conferência dos Estados Francófonos, que aconteceu na capital do Níger, Niamey ${ }^{9}$, encontro do qual nasce a Agência para a Cooperação Cultural e Técnica (ACCT) ${ }^{10}$, órgão de união dos países francófonos e de ajuda para seu desenvolvimento.

Foi nesse momento histórico que se tomou consciência de uma língua francesa não mais pertencente somente aos franceses.

E foi com o revigoramento da literatura francófona que também o momento da Négritude, nascido já em 1930 por obra de Aimé Césaire e Léopold Sédar Senghor, retomou impulso.

Não se deve esquecer, finalmente, que é em 1948, com a Anthologie de la nouvelle poésie nègre et malgache de la langue française, coletânea de escritos feita por Léopold Sédar Senghor com prefácio de Jean-Paul Sartre, que a francofonia da África negra afirma sua independência em relação à francesa.

\footnotetext{
${ }^{6}$ [N.A.] X.Deniau, La francophonie, Paris, Presses Universitaires de France (" Que sais-je ? »), 1983, I⿳亠ेre ed., 2003, II ed., p.18

7 [N.A.] Paris, Editions Letouzey \& Ané, 1986

8 [N.A.] Paris, Libraire Larousse, 1969.

9 [N.A.] Primeira conferência dos Estados Francófonos, da qual nasce a Agência de Cooperação Cultural e Técnica, órgão intergovernamental da Francofonia e principal promotora da Conferência Bienal de Chefes de Estado dos Países de Língua Francesa, único instrumento de ligação entre os países francófonos para cooperação e desenvolvimento. A ideia de solidariedade estava emergindo e, em 1974, foi criado o Comitê Interministerial para os assuntos francofones.

${ }^{10}$ [N.A.] Agence de coopération culturelle et technique (ACCT), órgão que congrega países ou governos de língua ou cultura francesa.
} 
Esta breve premissa contribui para encontrar as coordenadas de um romance singular que chamou nossa atenção, não somente pela espontaneidade da escrita, pelo componente sociológico que se funde com as aventuras e desventuras da protagonista, mas também por sublinhar o caráter de autonomia da escrita que precisamente reclama a francofonia.

Trata-se do romance La fille de Nana-Benz. [Uma filha de Nana-Benz] ${ }^{11}$ publicado em 1996 em Lomé (Togo), pela editora Akpagnon, criada pelo notório escritor Yves-Emmanuel Dogbé, falecido em novembro de 2004.

Para abordar o estudo do romance, o primeiro de Edwidge Edorh, escritora que nasceu e vive no Togo - e do filme realizado logo após a publicação do livro pela Amey Film -, é necessário conhecer o palco dos acontecimentos, o milieu da autora.

O Togo, apesar de ser um pequeno território, sofreu, como outros países africanos, com vários regimes coloniais: primeiro os alemães, depois os franceses e os ingleses, colonizadores que exercitaram seus poderes sem consideração pelas populações locais.

A principal etnia, os euês ${ }^{1213}$, ocupava o território desde tempos imemoriais tanto que mesmo o nome Togo tem origem em um pequeno vilarejo euê, formado à beira-mar, do Golfo do Benim, de fato, o nome Togo em língua éwé, significa "to" água, "go" costa.

Os euês eram uma população que habitava tanto o Togo quanto o Benim e que unia a cultura animista à prática do vodu.

Esta tribo, característica por esta crença particular, em seguida da colonização, - o Togo declarou sua própria independência ${ }^{14}$ apenas em 1960 - tendo entrado em contato com a religião europeia, e em particular com o catolicismo, não modificou o próprio credo, mas o adaptou às novas "exigências".

Ainda hoje a população togolesa baseia os acontecimentos na magia, que distingue entre a boa e a má, tanto que ainda existe o Mercado dos Fetiches, onde se encontra carcaça de animais e, às vezes, até restos humanos, usados para feitiços diversos. Em suma, pensam que a vida seja regulada por eventos mágicos, crendo na existência de um Todo-Poderoso, um Deus que tudo pode e que escolhe alguns homens a eles poderes particulares.

\footnotetext{
11 [N.T.] Como o romance ainda não foi traduzido para o português, as traduções apresentadas ao longo do texto são do próprio tradutor.

12 [N.A.] Éwé de Hwè-Nà, ou seja, "habitante da planície".

${ }^{13}$ [N.T.] No Brasil encontramos com mais frequência os termos jejes, evés, euês ou daomeanos (em referência ao Daomé) para fazer referência a este povo.

14 [N.A.] Em 1958 se instalou o primeiro governo do Togo autônomo, guiado pela União das Forças da Mudança (sob liderança de Sylvanus Olimpio), que sustentava uma completa independência. Foi somente em abril de 1960 que se declarou independente e, no outono do mesmo ano, o Togo foi admitido nas Nações Unidas.
} 
No Togo e Benim, entre muitas etnias, se distinguem bem os Hula ${ }^{15}$, Seguidores da Píton, que consideram a Python regius - este é o nome científico - como um animal sagrado, que pode transformar um seguidor, em caso de perigo, em uma enorme cobra píton. É o caso do pai de Edwidge, a Vidio do romance, ou seja, La fille de Nana-Benæ, a protagonista, uma moça que vai à escola e ajuda a mãe no trabalho do mercado. Lemos na quarta capa:

"Uma filha de Nana-Benz" é também narrativa dos bastidores do ativismo de algumas mulheres de negócios togolesas cujo "profano" (o que é exterior ao mercado) não pode suspeitar da riqueza e da intensidade. ${ }^{16}$

Os seguidores da cobra Píton se diferenciam exteriormente pelas cinco incisões paralelas que têm no rosto. Como se lê no trecho a seguir:

\begin{abstract}
Ainda que fosse católico [meu pai] e unido à minha mãe pelo santo sacramento do casamento, ele dava grande importância às práticas tradicionalistas [sic]. Ele se orgulhava de pertencer à raça hula cuja particularidade exterior consiste em escarificações paralelas no rosto. Estes cinco pares de incisões nas têmporas, nas bochechas e na testa são traços de pertencimento à "píton sagrada", o ancestral totêmico do povo Hula. ${ }^{17,18}$
\end{abstract}

A altivez dos Hula e o respeito pela Píton vêm sublinhados por uma anedota que que o homem amava contar a ela:

\begin{abstract}
No dia seguinte da primeira noite de núpcias, nossa mãe que queria, no entusiasmo de casada, fazer o leito nupcial com seus amores, achou, enrolada sob o travesseiro de seu jovem esposo, uma enorme cobra píton cujo comprimento equivalia ao braço de um homem. Ela caiu para trás, desmaiada. E quando o velho Redoh chegou, chamado por seu filho, qual não foi a surpresa das pessoas naquela manhã. $\mathrm{O}$ velho homem, com um sorriso largo, conversava com a serpente, lhe fazia elogios por tê-lo honrado com sua presença na união de seu filho e sua nora. [...] estendeu os braços para ela, e a serpente se enrolou neles, depois ele saiu do quarto cantarolando alegremente. ${ }^{19,20}$
\end{abstract} 15 [N.T.] No texto original e no romance utiliza-se o termo "Péda" ao qual não encontramos referências no
português brasileiro. Apesar de demandar mais pesquisas, provavelmente faz referência ao povo hula (também
referenciados como xwla, popo, pla popo). Ver LARANJEIRA, Lia Dias. O culto da serpente no reino de Uidá.
Um estudo da literatura de viagem europeia. Séculos XVII e SVIII. Salvador: Edufba. 2015. Disponível em:
https://repositorio.ufba.br/ri/bitstream/ri/29102/1/o_culto_da_serpente_EDUFBA_2015.pdf
16 [N.T.] Optamos por traduzir também os trechos citados do romance, mas apresentamos os originais em
notas. "La fille de Nana-Benz" est aussi le récit des dessous de l'activisme débonnaire de certaines de ces
femmes d'affaires togolaises, dont le "profane" (celui qui est extérieur au marché) ne peut soupçonner la ri-
chesse et l'intensité.

17 [N.A.] E. Edorh. La Fille de Nana-Benz, Lomé, Éd. Akpagnon, 1996, p. 17.

18 [N.T.] Quoique catholique [mon père] uni à ma mère par le saint sacrement du mariage, il accordait une grande importance aux pratiques traditionnalistes [sic]. Il s'enorgueillait d'appartenir à la race péda, dont la particularité extérieure consiste en des scarifications parallèles sur le visage. Ces cinq paires d'incisions aux tempes, sur les joues et le front dont des traits d'appartenance au "python sacré", l'ancêtre totémique du peuple Péda.

${ }^{19}$ [N.A.] E. Edorh. La Fille de Nana-Benz, Lomé, Éd. Akpagnon, 1996, p. 17-18.

${ }^{20}$ [N.T.] Au lendemain de leur première nuit de noces, notre mère qui voulait, dans l'enthousiasme de mariée, dresser le lit nuptial de ses amours, trouva, lové sous l'oreiller de son jeune époux, un énorme python dont la longueur équivalait au bras d'un homme. Elle tomba à renverse, évanouie. Et quand le vieux Redoh arriva, 
Em La Fille de Nana-Benz, romance autobiográfico, Edorh denuncia com muita força, a mistura de credos devida à colonização.

Sua mãe é uma Nana-Benz ${ }^{21}$. Assim são chamadas as mulheres ricas que trabalham no mercado. Nana do uso notório do francês familiar para femme [mulher] e jeune fille [moça]; Benz porque todas estas mulheres usavam um Mercedes-Benz.

E é ali mesmo, no mercado, que Vidio, enquanto limpava sua barraca encontra os fetiches,

Eu limpava, como sempre, cantos e recantos do nosso lugar naquele dia, quando a vassoura trouxe na minha direção nozes de cola ${ }^{22}$ e moedas. Diante de mim, se espalharam quatro nozes de cola vermelhas, quatro brancas, sete moedas de cinco francos e outras setes de dez francos. Eu fiz delas um monte no meio do corredor e me ocupava de tirar os tecidos da banca, quando gritos me alcançaram. . $3,24^{2}$

Fetiches que, digamos, lhe arruinarão a adolescência. É por este episódio que começa o drama, porque todos acreditam que ela esteja marcada pela má-sorte. E um país em que tudo é marcado pela boa ou má sorte, em que os feiticeiros governam a vida, ser afetado negativamente por eles torna-se um impedimento para a própria vida.

As desventuras se sucedem incansavelmente; o dinheiro que desparece, deixando no lugar estranhos braceletes:

Dois milhões. Desaparecidos como que por encanto. Criaram asas. Volatilizados. No seu lugar, dois braceletes entrelaçados, parecidos com os que foram confiados ao padre Paul. Quem teria entrado no quarto?25,26

appelé par son fils, quelle ne fut la surprise des gens cette matinée-là. Le vieil homme, avec un large sourire, s'entretenait avec le serpent, lui faisant des compliments pour avoir bien voulu honorer de sa présence l'union de son fils et sa bru. [...] lui tendit les bras, autour duquel le python s'enroula, puis il sortit de chambre en chantonnant gaiement.

21 [N.A.] Nana-Benz. Matronas protagonistas dos mercados como os de Lomé, foram administradoras do monopólio togolês das décadas florescentes de 1970-1980 e tornaram-se lendárias pelas fortunas que lhes permitiam exibir Mercedes-Benz.

22 [N.T.] Nos cultos brasileiros de matriz africana, as nozes de cola são chamadas de Obi. Trata-se, provavelmente, de referência aos frutos da espécie Cola acuminata que apresenta as cores branco e vermelho referenciadas no texto.

${ }^{23}$ [N.A.] E. Edorh. La Fille de Nana-Benz, Lomé, Éd. Akpagnon, 1996, p. 11.

${ }^{24}$ [N.T.] Je nettoyais, comme d'habitude, coins et recoins de notre place ce jour-là, quand le balai ramena vers moi des colas et des jetons. Devant moi, s'étalaient quatre noix de cola rouges, quatre blanches, septe pièces de cinq francs, septe autres de dix francs. J'en fis un tas au milieu de l'allée et m'occupais à sortir les tissus du magasin, quand des cris me parvinrent.

25 [N.A.] E. Edorh. La Fille de Nana-Benz. Lomé, Éd. Akpagnon, 1996, p. 20

${ }^{26}$ [N.T.] Deux millions. Disparus comme par enchantement. Envolé. Volatisés. A leur place, deux bracelets entrelacés, pareils à ceux confiés au père Paul. Qui était entré dans la chambre? 
A luta contra a má sorte determina continuadas visitas, com a mãe, ao Charlatão (charlatan no texto): Nós fomos levadas à casa de um charlatão de nome Sodoga para passarmos por uma humilhante provação. ${ }^{27} 28$

Em francês, assim como em italiano o termo exprime um sentido pejorativo, quer dizer enganador, pessoa que explora a credulidade pública, enquanto, como vem registrado no grande dicionário Robert, na África francófona, não tem valor negativo: de fato, se lê ad vocem: "Em francês da África (não pejorativo). Aquele que tem poderes de adivinhação, de cura." 29

Depois, descobriremos, ao final do romance - graças à confissão da tia Reine -, que tudo aconteceu por obra de uma tia, a tia Sista, e que a magia e os feiticeiros não tinham nada a ver com os fatos:

Foi Sista, minha filha. - conta à beira da morte Reine, uma das tias de Vidio, à ela e à sua mãe - Eu surpreendi, ela e nossa mãe, conversando sobre isso. Sista se culpava por ter causado a infelicidade de Vidio querendo se vingar. Ao mesmo tempo, ela não podia, ou melhor, não queria tomar a atitude de te pedir perdão e se reconciliar com você, Vidio. ${ }^{30,31}$

Edwidge, no obstante tenha sido educada no Togo e tenha estudado e sobretudo vivido exclusivamente neste país, é muito crítica em relação à forma de crença da mãe.

Um acontecimento que confirma esta confusão de credos é o que acontece quando a Nana-Benz encontra um outro feitiço no jardim e é acometida por uma doença. Naquela ocasião o pai Hula, católico ${ }^{32}$, ao invés de se dirigir ao feiticeiro, chama um sacerdote, o qual para curar a mulher realiza um ritual semelhante ao dos melhores feiticeiros ou charlatães.

Naturalmente que, estando apenas impressionada, a mulher se recupera rapidamente. Todo isso nos faz, no entanto, refletir e entender como é impossível mudar rapidamente uma cultura. Mesmo que tantos anos de colonização no Togo tenham colocado lado a lado as suas crenças e os nossos santos! É curioso ver, no filme baseado no romance, o Charlatão realizar os seus rituais de magia diante da imagem da paixão de Cristo.

\footnotetext{
27 [N.A.] E. Edorh. La Fille de Nana-Benz. Lomé, Éd. Akpagnon, 1996, p. 29

${ }^{28}$ [N.T.] Nous fûmes conduits chez un charlatan du nom Sodoga pour subir l'humiliante épreuve de l'ordalie.

${ }^{29}$ [N.T.] En franç. d'Afrique (non péjoratif). Celui qui a des pouvoirs de devin, de guérisseur.

30 [N.A.] E. Edorh. La Fille de Nana-Benz. Lomé, Éd. Akpagnon, 1996, p. 98

31 [N.T.] C'est Sista, ma sœur, - [...] - Je les ai surprises elle et notre mère en train d'en discuter. Sista se reprochait d'avoir rendu malheureuse Vidio en roulant se venger. En même temps, elle ne pouvait, ou plutôt, ne voulait pas faire le geste de pardon et de réconciliation vers toi, Vidio.

32 [N.A.] Esta é uma outra mistura bem africana.
} 
$\mathrm{Na}$ nossa opinião, o filme ${ }^{33}$ é importantíssimo porque é verdadeiro; os intérpretes, de fato, não são atores profissionais, mas são, em parte, os verdadeiros protagonistas da história, assim como os feiticeiros e seus "serviços".

Através da leitura do romance fica evidente que a autora ao escrevê-lo não quis somente contar sua própria história, mas buscar emancipar através de sua vivência a mulher togolesa e denunciar aos seus compatriotas os males de seu país.

Lê-se, em uma das páginas do final do romance, a sua reflexão sobre as mulheres togolesas:

Eu me convenço, cada vez mais, que a mulher togolesa precisa ser ambiciosa.
Infelizmente, ela se contenta com um lugar no fundo da cozinha, com um espa-
cinho no coração de seu homem invadidos pelas outras, como se o território lhe
tivesse ditado sua política de relevo e de superfície. [...]. Me recuso a fazer uma
personagem pequena, que, na falta de coisa melhor, vende seu sorriso e sua pele.
Eu me entrego seriamente ao trabalho, ocultando meus sofrimentos, recoberta
pela febre do sucesso. ${ }^{34,35}$

Para concluir, gostaria de ressaltar ainda o mérito da jovem autora de haver sustentado sua batalha a favor da mulher togolesa, no Togo, sem polêmicas, sem, como se diz, forçar a mão, mas com habilidade de deixar ao fruidor, ou melhor às fruidoras, a liberdade de traçar sozinhas as conclusões que, sem dúvida, resultam edificantes, precursoras de um desejo de renovação e de independência intelectual e social.

Recebido em: 26/04/2021.

Aprovado em: 17/07/2021.

\footnotetext{
33 [N.A.] O filme realizado com contribuição do Ministério da Cultura Togolês.

34 [N.A.] E. Edorh. La Fille de Nana-Benz. Lomé, Éd. Akpagnon, 1996, p. 84-85

35 [N.T.] Je me persuade de plus en plus que la fille togolaise a besoin d'être ambitieuse. Malheureusement, elle se contente de la place au fond de la cuisine, du petit espace dans le cœur de son homme envahi par les maîtresses, comme si le territoire lui avait dicté sa politique de relief et de superficie. [...] Je me refuse à jouer au petit personnage, faute de mieux, vend son sourire et sa peau. Je me mis sérieusement au travail, occultant mes souffrances, galvanisée par la fièvre du succès.
} 